\title{
İşsizlik ile Sigara Üzerinden Alınan Vergiler Arasındaki İlişki: Türkiye Analizi
}

\author{
Emrah GÜLAY* $\quad$ Ahmet ÖZEN**
}

\begin{abstract}
$\ddot{O} Z$
Türkiye'de sigara tüketimi ve işsizlik oranı arasındaki ilişkiyi inceleyen birçok çalışmanın aksine tütün üzerinden alınan vergiler ile işsizlik oranı arasındaki ilişkinin daha önce ele alınmamış olması, bu çalışmanın literatüre olan katkısı açısından önem taşımaktadır. Çalışmada aylık olarak ele alınan veriler 2006:1-2015:7 dönemleri arasını kapsamaktadır. Çalışmanın amacı, Türkiye'de tütün üzerinden alınan vergiler ile işsizlik oranları arasında uzun dönemli bir ilişkinin var olup olmadiğını belirlemektir. Bu doğrultuda, değiş̧kenlerin durağanlığı birim kök testleri ile araştırılmış ve yapısal kırllmalarında dikkate alındĭ̆ Otoregresif Dağıtılmış Gecikme Modeli tahminlenerek, iki seri arasındaki uzun dönemli ilişski açıklanmıştır. Elde edilen sonuçlara göre, işsizlik oranlarında meydana elen artışı uzun dönemde tütün üzerinden alınan vergileri arttırdı̆g görülürken, kısa dönemde işsizlik oranlarındaki artışın tütün üzerindeki vergilere negatif bir etki yaptığ belirlenmiştir.
\end{abstract}

Anahtar Kelimeler: Tütün Üzerinden Alınan Vergiler, İşsizlik Oranları, Eşbütünleşme, Yapısal Kırllma, ARDL Modeli

JEL Sinıflamasi: C22, C51, E24, H20

\section{The Relationship Between Tobacco Tax and Unemployment: Turkey Analysis}

\begin{abstract}
There are a number of studies focusing on the relationship between the tobacco consumption and unemployment rate in Turkey. Therefore, this study contributes to the literature because the relationship between tobacco tax and unemployment rate has not been studied before. The objective of this study is to determine the relationship between the tobacco tax and unemployment rate in Turkey over the period 2006:1-2015:7. In this context, Unit root tests have been exploited to check the integration order of the variables, and the Autoregressive Distributed Lag Model including structural breaks is employed to explain the long-run relationship between the tobacco tax and unemployment rate. The findings of this study show that while an increase in unemployment rate is to raise tobacco tax in the long-run, an increase in unemployment rate is to decrease tobacco tax in the short-run.
\end{abstract}

Key Words: Tobacco tax, Unemployment rate, Cointegration, Structural break, ARDL Model JEL Classification: C22, C51, E24, H20

\section{GİRIŞ̧}

Çalışma kabiliyetine sahip olan ancak mevcut durumuyla herhangi bir işte istihdam edilmeyenlerin bulunması durumu şeklinde tanımlanan işsizlik, sosyoekonomik birçok açıdan incelenebilir. Örneğin işsizliğin ekonomik açıdan ciddi

\footnotetext{
*Yrd. Doç. Dr. Dokuz Eylül Üniversitesi İ.İ.B.F., Ekonometri Bölümü, emrah.gulay@deu.edu.tr.

** Doç. Dr., Dokuz Eylül Üniversitesi İ.İ.B.F., Maliye Bölümü, ahmet.ozen@ deu.edu.tr.
} 
katma değer kaybına yol açabileceği, mali açıdan devlet üzerinde ciddi yük oluşturabileceği ve sosyal açıdan toplumsal bir huzursuzluk doğurabileceği ifade edilebilir. Elbette işsizliğin kişi üzerinde oluşturabileceği davranışsal farklılıklar da ortaya çıkabilir. İşsizlik, özelikle sağlıkla ilgili davranışsal durumlarda daha fazla kötüleşmeye neden olabilmektedir (Montgomery vd., 1998:26). Bu tür davranışsal gözlemlerden biri de sigara bağımlılığıdır.

Sigara tüketimi bir ülkenin en ciddi sosyal sorunlarından biri olarak dikkat çekmektedir. Nüfus artışıla uyumlu bir şekilde sigara tüketiminin de artması özellikle az gelişmiş ve gelişmekte olan ülkelerde görülen bir tüketim davranışıdır. Nitekim bu durum Türkiye açısından da geçerli olup, ülkemizde geleneksel olarak sigara tüketicisi olma davranışı gözlenmektedir (Temiz, 2010:52). Sigara tüketimine neden olan faktörler arasında ise bireyin içinde bulunduğu psikolojik durum, sosyal çevre ve ekonomik durum gösterilebilir. Öte yandan sigaranın gerek kullanan birey üzerinde içsel maliyeti gerekse diğer bireyler üzerinde dışsal maliyetleri ortaya çıkmaktadır. Bu tür dışsallıkların engellenebilmesi için literatürde günah vergileri şeklinde de nitelendirilebilen vergisel tedbirler uygulanabilmektedir. Böylece vergilendirme ile sosyal açıdan arzulanmayan sosyal davranışları engellemek veya azaltmak mümkündür (Sakınç ve Cura, 2012: 54).

Sigara tüketimi ve sigara üzerinden alınan vergiler arasındaki yoğun bir etki söz konusudur. Öyle ki sigara tüketimi arttıkça sigara üzerinden alınan vergilerde de artışın olacağı kaçınılmazdır. Bununla birlikte işsizliğin sigara üzerinden alınan vergiler üzerinde nasıl bir etki oluşturabileceği de araştırma konusu yapılabilir. Nitekim bu çalışmada işsizlikteki değişimin sigara üzerinden alınan vergilerde hangi yönde bir etkide bulunduğu inceleme konusu yapılacaktır.

\section{LITERATÜR ÖZETI}

Bugüne kadar işsizlik ile sigara arasındaki ilişkileri farklı açılardan ele almış olan bir dizi çalışma yürütülmüştür. Bu tür çalışmaları gruplandırarak Tablo 1 hazırlanmıştır.

Tablo 1. Literatür Özeti

\begin{tabular}{|l|l|}
\hline $\begin{array}{l}\text { Vergi artışlarının toplam istihdam üzerindeki etkilerini } \\
\text { araştıran çalışmalar }\end{array}$ & $\begin{array}{l}\text { Jacobs vd, (2000), Barber vd, } \\
\text { (2008), Hu vd. (2008) }\end{array}$ \\
\hline $\begin{array}{l}\text { Sigara tüketimindeki azalmanın toplam istihdam üzerindeki } \\
\text { etkisini araştıran çalışmalar }\end{array}$ & $\begin{array}{l}\text { Jacobs vd. (2000), McNicoll ve } \\
\text { Boyle, (1992), Buck vd., (1995), } \\
\text { Merwe, (1998a, 1998b), Merwe ve } \\
\text { Abedian, (1999), Irvine ve Sims, } \\
(1997)\end{array}$ \\
\hline $\begin{array}{l}\text { Önceden işsiz kalmış bireylerin diğerlerine nazaran daha } \\
\text { fazla sigara tüketim alışkanlıklarının olduğunu tespit eden } \\
\text { çeşitli çalışmalar }\end{array}$ & $\begin{array}{l}\text { Montgomery vd, 1998; Falba, 2005; } \\
\text { Bolton \& Rodriguez, 2016; Wang } \\
\text { vd., 2016 }\end{array}$ \\
\hline $\begin{array}{l}\text { İşizliğin sigara içme ihtimalini iki katına çıkardığını ortaya } \\
\text { koyan çalışmalar }\end{array}$ & Arcaya vd., 2014 \\
\hline $\begin{array}{l}\text { İşizlik ile sigara tüketimi arasındaki ilişkiyi psikolojik } \\
\text { açıdan ele alan ve işsizliğin yarattığı içsel çöküş ve kendini } \\
\text { çaresiz hissetme gibi psikolojik etkenlerin de sigara } \\
\text { tüketimini artırdığını savunan çalışmalar }\end{array}$ & Vogli \& Santinello, 2005 \\
\hline
\end{tabular}




\begin{tabular}{|c|c|}
\hline $\begin{array}{l}\text { İşsizliğin gençler ve özellikle kadınlar üzerinde sigara içme } \\
\text { oranını arttırdığı tespit eden çeşitli çalışmalar }\end{array}$ & $\begin{array}{l}\text { Hammarström \& Janlert, 1994; } \\
\text { Weden vd., } 2006\end{array}$ \\
\hline $\begin{array}{l}\text { İşsizliğin yoğun olduğu bölgelerde yaşayan bayanların } \\
\text { sigara içme ihtimalinin yükseldiğini veya işsizliğin yoğun } \\
\text { olduğu bölgede sigara tüketimin de arttığını ortaya koyan } \\
\text { çalışmalar }\end{array}$ & $\begin{array}{l}\text { Karvonen vd., 2008, Ohlander vd., } \\
2006\end{array}$ \\
\hline $\begin{array}{l}\text { İşsizliğin sigara tüketiminde artışa neden olmadığını tespit } \\
\text { eden çalışmalar }\end{array}$ & Morris vd., 1992 \\
\hline $\begin{array}{l}\text { İşsizlikteki artışın sigara tüketimini azalttığını ve sigara } \\
\text { fiyatları ile sigara tüketimi arasında negatif bir ilişki } \\
\text { olduğunu savunan çalışma }\end{array}$ & Temiz, 2010 \\
\hline $\begin{array}{l}\text { Sigara üzerindeki vergi oranlarının özellikle gençler ve } \\
\text { yoksullar üzerinde sigara tüketiminde azalmaya neden } \\
\text { olduğunu ortaya koyan çalışma }\end{array}$ & Chaloupka vd., 2012 \\
\hline $\begin{array}{l}\text { Sigara üzerinden alınan vergilerde artışın günlük çok az } \\
\text { sigara içenlerin sigara tüketiminde belirgin oranda azalışa } \\
\text { yol açtığını savunan çalışma }\end{array}$ & Önder \& Yürekli, 2016 \\
\hline $\begin{array}{l}\text { İşsizlik oranındaki ve sigara fiyatlarındaki artışlar sigara } \\
\text { tüketimini azaltıcı etkiler yaratabildiğini ifade eden çalışma }\end{array}$ & Karaöz vd., 2010 \\
\hline $\begin{array}{l}\text { İşsizliğin ve sigara fiyatlarındaki artışın sigara tüketimini } \\
\text { azalttığ } 1 \text { tespit eden çalışma }\end{array}$ & Oğuztürk \&Gülcü, 2012 \\
\hline $\begin{array}{l}\text { Bağımsız veya bir işverene bağlı olarak çalışanların işsiz } \\
\text { bireylere göre daha fazla sigara içme eğilimde oldukları } \\
\text { sonucuna ulaşılan çalışma }\end{array}$ & Kılıç, 2014 \\
\hline 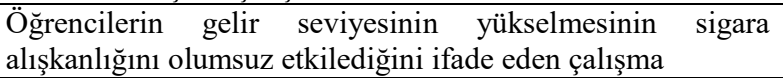 & Çalışkan, 2015 \\
\hline $\begin{array}{l}\text { İşsizlik ile sigara üzerinden alınan vergi oranları arasında bir } \\
\text { ilişkinin olmadığını tespit eden çalışma }\end{array}$ & Golden vd, 2014 \\
\hline
\end{tabular}

Kaynak: Tarafımızdan hazırlanmıştır.

Öte yandan sigara tüketimi ile toplum sağlığı, tüketici fiyat endeksi veya kamu gelirleri arasındaki ilişkileri ele alan çeşitli çalışmalar da yer almaktadır. Bununla birlikte işsizliğin sigara üzerinden alınan vergiler üzerinde ne yönde bir etkide bulunduğunu araştıran çalışmalar son derece sınırlıdır. Nitekim işsizlik ile sigara üzerinden alınan vergiler arasındaki ilişki analize tabi tutularak ülkemizdeki çalışma literatüre bu yönde katkı sağlamayı amaçlamaktadır.

\section{VERİ SETİ VE YÖNTEM}

Çalışmanın bu bölümünde kullanılan veri setleri ve analiz kısmında uygulanan yöntemler ayrıntılı bir şekilde ele alınmaktadır.

\section{A. Veri Seti}

Çalışmada kullanılan veri seti tütün tüketimi üzerinden alınan vergiler ve işsizlik oranlarından oluşmaktadır. Tütün üzerinden alınan vergiler KDV ve ÖTV kapsamında yer almakta olup, kullanılan veriler bunların toplamını ifade etmektedir. Ele alınan veriler aylik olup 2006M1- 2015M7 dönemini kapsamaktadır. Veri setlerinin tamamı Merkez Bankası Elektronik Veri Dağıtım sisteminden elde edilmiştir. Veri setlerinin aylık olmasından dolayı her iki veri seti mevsimsellikten arındırılmıştır. Serileri mevsimsellikten arındırmak için Victor Gomez ve Agustin Maravall (1997) tarafından geliştirilen TRAMO/SEATS yöntemi kullanılmıştır. TRAMO/SEATS yöntemi mevsimsel düzeltme yöntemine dayanan bir ARIMA modelidir. Aynı zamanda, veri 
setlerinin logaritması alınarak logaritmik veriler üzerinden analizler gerçekleştirilmiştir. İstatistiksel açıdan ele aldığımızda, logaritmik veriler üzerinde çalışmamızın nedenlerden birisi; bağımlı ve bağımsız değişken arasındaki doğrusal olmayan ilişki problemini ortadan kaldırmaktır. İkinci bir neden ise, doğal logaritmanın kullanılmasının ekonomik değişkenler arasındaki ilişkinin yorumlanmasında oldukça uygun olmasıdır.

\section{B. Yöntem}

Tütün üzerinden alınan vergiler ile işsizlik oranı arasındaki ilişkinin varlığı için zaman serisi analiz yöntemleri uygulanmıştır ve bu bağlamda aşağıdaki regresyon denklemi ele alınmaktadır.

LTUTUN $_{t}=\alpha_{1}+\beta_{1}$ LISZO $_{t}+\varepsilon_{t}$

Burada LTUTUN değişkeni tütün üzerinden alınan vergilerin logaritmasını, LISZO değişkeni ise işsizlik oranının logaritmasına karşılık gelmektedir. $\varepsilon_{t}$ ise modelde yer alan hata terimini temsil etmektedir. Bu çalışmanın temel amacı aşağıdaki hipotezi test etmektir.

$\mathrm{H}_{0}$ : Tütün üzerinden alınan vergiler ile işsizlik oranı arasında uzun dönemli bir ilişki yoktur

$\mathrm{H}_{\mathrm{A}}$ : Tütün üzerinden alınan vergiler ile işsizlik oranı arasında uzun dönemli bir ilişki vardır

Çalışmanın amacı doğrultusunda, tütün üzerinden alınan vergiler ile işsizlik oranı arasında uzun dönemli bir ilişkinin varlığını incelemeden önce serilerin durağan olup olmadığı veya birim kök içerip içermediği birim kök testleri kullanılarak belirlenmiştir.

\section{Birim Kök Testi}

Serilerin bütünleşme derecesinin belirlenmesinde literatürde en çok kullanılan yöntemlerden biri Dickey and Fuller (1979) tarafından önerilen Augmented Dickey Fuller (ADF) testidir. ADF testine alternatif bir test ise Phillips and Perron (1988) tarafından önerilen Phillips-Perron (PP) testidir.

PP testinin ADF testine göre fark1, birim kök testinde ardışık korelasyon sorununun düzeltilmesidir. Bu çalışmada, her iki birim kök testide kullanılmıştır. Birim kök testi öncesinde durağanlık testinin doğruluğu açısından serilerin grafiklerinin incelenmesi önem arz etmektedir. Bu doğrultuda, her iki serininde grafiği Şekil 1'de verilmektedir.

Tütün üzerinden alınan vergilere ait serinin zaman içerisinde artan bir trende sahip olduğu görülmektedir. Bu nedenle, LTUTUN değişkeninin birim kök testine ilişkin sonuçları yorumlanırken sabit ve trend içeren modeller dikkate alınmaktadır. LISZO değişkeni içinde sabit ve sabit ve trend içeren modeller temel alınarak yorumlama yapılmaktadır. Tablo 2, LTUTUN ve LISZO serileri için birim kök testi sonuçlarını göstermektedir. 
LTUTUN
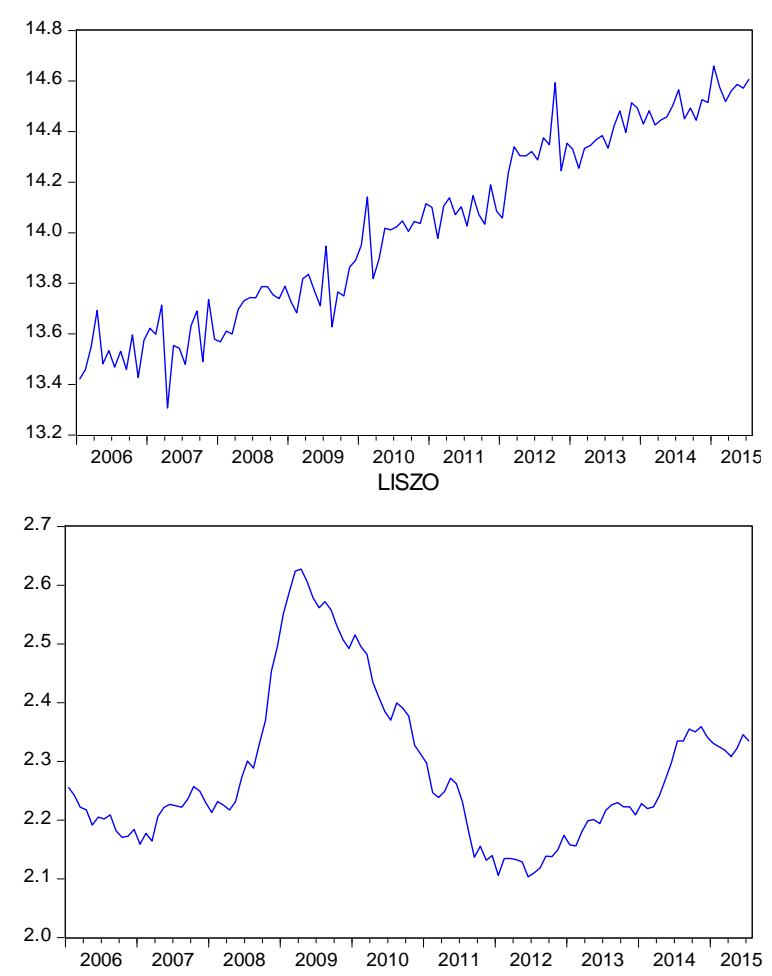

Şekil 1: Değişkenlerin Zamana Göre Grafikleri

Tablo 2: Birim Kök Testi Sonuçları

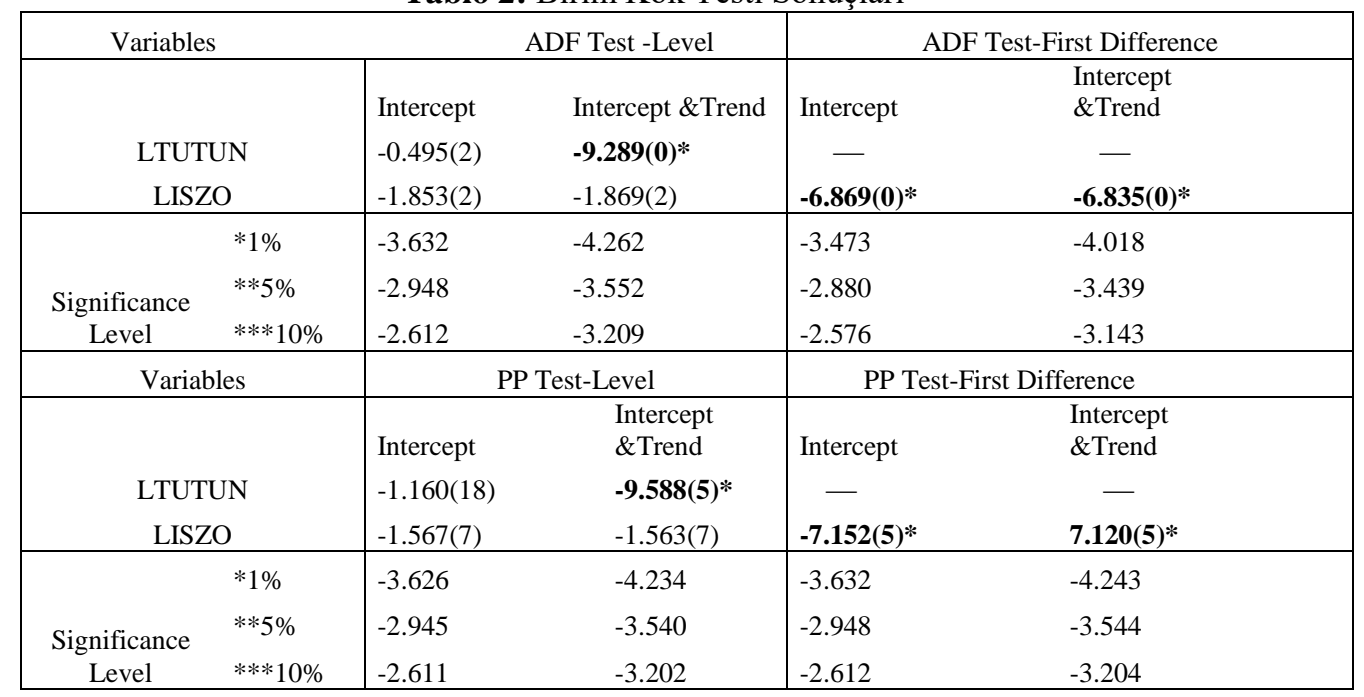

Tablo 2'den elde edilen sonuçlara göre, LTUTUN değişkeninin sabit ve trend içeren modelde düzeyde durağan I(0) olduğu görülmektedir. Bu nedenle, bu 
değişkenin birinci farkına ilişkin birim kök testi sonuçları verilmemektedir. LISZO değişkeninin ise düzeyde durağan olmadığı, birinci farklı alındıktan sonra durağan hale geldiği, I(1), belirlenmiştir. Ancak, serilerde yapısal kırılma olması durumunda ADF ve PP testleri yanlı sonuçlar doğuracağından, her iki seriye, seride bir yapısal kırılmaya izin veren Zivot ve Andrews (1992) birim kök testi uygulanmıştır. Zivot ve Andrews birim kök testi sonuçları Tablo 3'te gösterilmektedir.

Tablo 3: Zivot ve Andrews Birim Kök Testi Sonuçları

\begin{tabular}{lcccccc}
\hline & \multicolumn{2}{c}{ Sabitte Kırılma } & \multicolumn{2}{c}{ Trendde Kirılma } & \multicolumn{2}{c}{$\begin{array}{c}\text { Kabit ve Trendde } \\
\end{array}$} \\
\cline { 2 - 7 } Değişkenler & y11/ay & t-istatistiği & y1l/ay & t-istatistiği & y11/ay & $\begin{array}{c}\text { t- } \\
\text { istatistiğ }\end{array}$ \\
\hline LTUTUN & $2012 \mathrm{M} 2$ & $-5.02^{* *}$ & $2007 \mathrm{M} 5$ & $-4.80^{*}$ & $2012 \mathrm{M} 2$ & $-5.40^{*}$ \\
LISZO & $\mathbf{2 0 1 0 M 9}$ & $\mathbf{- 3 . 5 8}$ & $\mathbf{2 0 1 0 M 1 0}$ & $\mathbf{- 2 . 4 4}$ & $\mathbf{2 0 1 0 M 9}$ & $\mathbf{- 3 . 3 3}$ \\
\hline
\end{tabular}

*,** : Serinin yapısal kırılma altında birim kök içerdiğini söyleyen sıfır hipotezi sırayla \%1 ve \%5 düzeyinde reddedilmektedir.

Tablo 3'ten elde edilen sonuçlata göre, LTUTUN değişkeninin seride mevcut yapısal kırılmadan dolayı sahte birim kök içerdiği ve nedenle serinin gerçekte durağan olduğu belirlenmiştir. LISZO değişkeni ele alındığında, serinin kendisinde yapısal kırılma olduğu ve serinin durağan olmadığ elde edilen test istatistiklerinden görülmektedir.

Birim kök testi sonuçları LTUTUN ve LISZO değişkenlerinin aynı düzeyde durağan olmadıklarını göstermektedir. $\mathrm{Bu}$ durumda, iki seri arasındaki uzun dönemli ilişkinin varlığı, değişkenlerin aynı düzeyde olmamalarına izin veren Otoregesif Dağıtılmış Gecikme Modeli (ARDL) kullanılarak incelenmiştir.

\section{Eşbütünleşme Testi}

Eşbütünleşme testleri, makroekonomik zaman serisi değişkenleri arasındaki uzun dönemli ilişkiyi tahmin etmek için kullanılmaktadır. ARDL modeli yaklaşımı, başlangıçta Peseran ve Shin(1999) tarafından ele alınmış daha sonra Pesaran et al., (2001) yaptıkları çalışmalar sonucu geliştirilmiştir. Bu yaklaşım diğer eşbütünleşme metotlarıyla karşılaştırıldığında birçok avantajlara sahiptir. Temel avantajı, elimizdeki serilerin I(0), I(1) veya parçalı bütünleşik olup olmadığına bakmaksızın uygulanabilir olmasıdır(Gülay ve Pazarlığlu, 2008:100). Bu yaklaşımın diğer bir avantajı ise, küçük örneklemlerde sağlam ve etkin sonuçlar ile birlikte uzun dönem katsayılarının tutarlı ve yansız olmasını sağlamasıdır. Ayrıca, dinamik hata düzeltme modeli(ECM) ARDL'den elde edilebilmekte ve böylece kısa dönem dinamikleri ile uzun dönem dengesi, uzun dönem bilgisini kaybetmeden bütünleşebilmektedir.

ARDL modelini aşağıdaki gibi yazabiliriz (Mallick ve Agarwal, 2005:12):

$\Phi(\mathrm{L}, \mathrm{p}) \mathrm{y}_{\mathrm{t}}=\alpha_{0}+\sum_{\mathrm{i}=1}^{\mathrm{k}} \beta_{\mathrm{i}}\left(\mathrm{L}, \mathrm{q}_{\mathrm{i}}\right) \mathrm{x}_{\mathrm{it}}+\mathrm{u}_{\mathrm{t}}$ 
Burada;

$$
\begin{aligned}
& \Phi(\mathrm{L}, \mathrm{p})=1-\Phi_{1} \mathrm{~L}^{1}-\Phi_{2} \mathrm{~L}^{2}+\ldots \ldots-\Phi_{\mathrm{p}} \mathrm{L}^{\mathrm{p}} \\
& \beta_{\mathrm{i}}\left(\mathrm{L}, \mathrm{q}_{\mathrm{i}}\right)=\beta_{0} \mathrm{~L}^{0}+\beta_{\mathrm{i} 1} \mathrm{~L}^{1}+\beta_{\mathrm{i} 2} \mathrm{~L}^{2}+\ldots . .+\beta_{\mathrm{iq}} \mathrm{L}^{\mathrm{q}}, \quad \mathrm{i}=1,2, \ldots, \mathrm{k},
\end{aligned}
$$

olarak gösterilir. Aynı zamanda, $\alpha_{0}$ sabit katsayı; $\mathrm{y}_{\mathrm{t}}$ bağımlı değişken; $\mathrm{x}_{\mathrm{t}}$ açıklayıcı değişken ve L gecikme operatörüdür.

$$
\mathrm{y}_{\mathrm{t}}=\mu+\sum_{\mathrm{i}=1}^{\mathrm{k}} \beta_{\mathrm{i}} \mathrm{x}_{\mathrm{it}}+\varepsilon_{\mathrm{t}}
$$

Uzun dönem ilişkiyi veren katsayıların tahmini için, denklemi aşağıdaki gibi yazabiliriz.

$$
\begin{aligned}
& \hat{\mu}=\frac{\alpha_{0}}{1-\left(\Phi_{1}+\Phi_{2}+\ldots+\Phi_{\mathrm{p}}\right)} \\
& \hat{\beta}=\frac{\beta_{\mathrm{i} 0}+\beta_{\mathrm{i} 1}+\beta_{\mathrm{i} 2}+\ldots+\beta_{\mathrm{iq}}}{1-\left(\Phi_{1}+\Phi_{2}+\ldots+\Phi_{\mathrm{q}}\right)}, \quad \mathrm{i}=1,2, \ldots \mathrm{k}
\end{aligned}
$$

Değişkenler arasındaki kısa dönem ilişkiyi ortaya koyan hata düzeltme denklemi aşağıdaki şekilde yazılabilir.

$$
\begin{aligned}
& \begin{aligned}
\Delta \mathrm{Y}_{\mathrm{t}} & =\alpha_{0}+\sum_{\mathrm{i}=1}^{\mathrm{k}} \beta_{\mathrm{i} 1} \Delta \mathrm{X}_{\mathrm{it}}-\sum_{\mathrm{i}=1}^{\hat{\mathrm{p}}-1} \Phi_{\mathrm{i} 1} \Delta \mathrm{y}_{\mathrm{t}-\mathrm{j}}-\sum_{\mathrm{i}=1}^{\mathrm{k}} \sum_{\mathrm{i}=1}^{\hat{\mathrm{q}}-1} \beta_{\mathrm{ij}} \Delta \mathrm{X}_{\mathrm{it}-\mathrm{j}} \\
& =-\Phi(1, \hat{\mathrm{p}}) \mathrm{ECM}_{\mathrm{t}-1}+\mathrm{u}_{\mathrm{t}}
\end{aligned} \\
& \mathrm{ECM}_{\mathrm{t}-1}=\mathrm{y}_{\mathrm{t}}-\sum_{\mathrm{i}=1}^{\mathrm{k}} \hat{\beta}_{\mathrm{i}} \Delta \mathrm{X}_{\mathrm{it}}
\end{aligned}
$$

$\mathrm{ECM}_{\mathrm{t}-1}$, hata düzeltme terimidir. Burada hata düzeltme terimi katsayıs1 $\Phi(1, \hat{p})$ uzun döneme doğru uyarlama hızını göstermektedir. Ayrıca, ARDL modeli gösterimi herhangi çokdeğişkenli örnekler için genelleştirilebilmektedir.

LTUTUN ve LISZO değişkenleri arasında uzun dönemli ilişkinin incelenmesi için ARDL testi kullanılmıştır. Zivot ve Andrews birim kök testinden elde edilen kir1lma noktalarından sadece 2007M5, 2010M10 ve 2012M2 anlamlı oldukları için modele dâhil edilmiştir.

$$
\begin{aligned}
& \Delta \text { LTUTUN }_{\mathrm{t}}=\mathrm{a}_{0}+\sum_{\mathrm{i}=1}^{\mathrm{m}} \mathrm{a}_{1 \mathrm{i}} \Delta \text { LTUTUN }_{\mathrm{t}-\mathrm{i}}+\sum_{\mathrm{i}=0}^{\mathrm{m}} \mathrm{a}_{2 \mathrm{i}} \Delta \text { LISZO }_{\mathrm{t}-\mathrm{i}}+\mathrm{a}_{3} \text { LTUTUN }_{\mathrm{t}-1}+\mathrm{a}_{4} \text { LISZO }_{\mathrm{t}-1}
\end{aligned}
$$

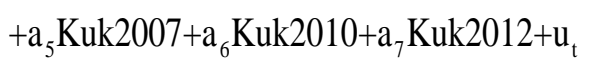


İlk olarak, LTUTUN ve LISZO değişkenleri arasındaki uzun dönemli ilişkinin varllğ 1 incelenmiştir. Sonuçlar Tablo 4'te verilmektedir.

Tablo 4: Sınır Testi için Gecikme Sayısının Belirlenmesi

\begin{tabular}{ccc}
\hline $\mathrm{m}$ & SIC & $\chi_{B G}^{2}$ \\
\hline 1 & -1.921 & 9.404 \\
2 & -2.041 & 7.859 \\
3 & -2.056 & 7.783 \\
4 & -2.040 & 14.602 \\
5 & -2.012 & 14.949 \\
6 & -1.947 & 20.827 \\
$\mathbf{7}$ & $\mathbf{- 1 . 9 0 4}$ & $\mathbf{2 9 . 7 9 3 * * *}$ \\
8 & -1.819 & 27.047 \\
\hline
\end{tabular}

Not: m, (8) numaralı denklemdeki gecikme saysidur. $\chi_{B G}^{2}$ Breusch-Godfrey ardaşı bağıllik sinamast istatistiğidir. *, ** ve *** işaretleri, sirasiyla $\% 1, \% 5$ ve \%10 düzeyinde hata terimi arasında ardışı bağımlilığ göstermektedir.

Tablo 4'te yer alan sonuçlara göre en küçük SIC kriterine sahip ve \%10, $\% 5$ ve \%1 için ardışı bağımlılık olmayan gecikme sayısı "7" olarak belirlenmiştir. $\mathrm{Bu}$ nedenle sınır testi "7" gecikmeli model için yapılarak, değişkenler arasında eşbütünleşme ilişkisinin olup olmadığı gösteren sonuçlar Tablo 5'te yer almaktadır.

Tablo 5: Sınır Testinde Hesaplanan F istatistiğinin Kritik Tablo Değeri İle Karşılaştırılması

\begin{tabular}{cccc}
\hline \multirow{2}{*}{$\mathrm{k}$} & F istatistiği & $\begin{array}{c}\text { \%5 anlamlılık düzeyindeki kritik değer } \\
\text { Ult sıst sınır }\end{array}$ & \\
\hline & 13.772 & 3.516 & 4.781 \\
\hline
\end{tabular}

Not: k, (8) numaralı denklemdeki bağımsız değişken sayı sayısıdır. Kritik değerler Pesaran vd. (2001:300)'deki Tablo CI(iii)'ten alınmışur.

Tablo 5'te elde edilen F istatistiği Peseran ve diğerleri tarafindan önerilen kritik tablo değerinden büyük olduğu için tütün üzerinden alınan vergiler ve işsizlik oranları arasında uzun dönemli bir ilişki bulunmaktadır. Uzun dönem katsayılarına ilişkin sonuçlar Tablo 6'da verilmektedir. 
Tablo 6: ARDL $(3,4)$ ve Hesaplanan Uzun Dönem Katsayıları

\begin{tabular}{ccc}
\hline Değişkenler & Katsay1 & t istatistiği \\
\hline Sabit & 12.183 & $24.102^{*}$ \\
LISZO & 0.618 & $2.710^{*}$ \\
Kukla2007 & 0.177 & $1.683^{* * *}$ \\
Kukla2010 & 0.290 & $3.218^{*}$ \\
Kukla2012 & 0.469 & $5.706^{*}$ \\
\hline
\end{tabular}

Not: Sadece anlamlı değişkenlerin katsayıları verilmektedir.

$*, * *, * * *$ sirasiyla $\% 1, \% 5$ ve $\% 10$ anlamlılık

düzeylerini göstermektedir

Tablo 6'da yer alan sonuçlar, işsizlik oranlarındaki \%1'lik bir artışın tütün üzerinden alınan vergileri \%0.618 oranında arttırdığını göstermektedir. Aynı zamanda, 2007M5, 2010M10 ve 2012M2 dönemlerinde meydana gelen yapisal kırılmaların tütün üzerinden alınan vergiler üzerinde pozitif bir etkiye sahip olduğu belirlenmiştir. Özellikle 2007 yllında Ulusal Tütün Kontrol Programı Eylem Planı'nın yürürlüğe girmesi ve 2008 yılından itibaren kapalı alanda sigara içimine kısıt gelmesi; 2012 yılında kaçak sigaraya yapılan operasyonların sıklığının artması neticesinde yasal sigaradaki 7 milyar adetlik tüketim artışı (http://www.haberturk.com.) sigara tüketiminde önemli kırılma dönemlerini göstermektedir. Işsizlik açısından ise özellikle 2010 yılı Ekim döneminde istihdam edilenlerin sayısı, geçen yılın aynı dönemine göre 953 bin kişi artarak, 22 milyon 972 bin kişiye yükselmiştir. Bu dönemde, tarım sektöründe çalışan sayısı 353 bin kişi, tarım dışı sektörlerde çalışan sayısı ise 600 bin kişi artmıştır (http://www.tuik.gov.tr). Bu durum ise kırılma açısından önemli bir gelişme olarak nitelendirilebilir.

Uzun dönem katsayılarına ilişkin diagnostik istatistikler Tablo 7'de yer almaktadır. Tablo 7'de yer alan diagnostik test sonuçlara göre, uzun döneme ilişkin model tüm varsayımları yerine getirmektedir.

Tablo 7: Uzun Dönem İlişkisine İlişkin Diagnostik Test Sonuçları

\begin{tabular}{ccc}
\hline & Test İstatistikleri & \\
& (Olasılık Değerleri) & Kullanılan Testler \\
\hline Normallik Varsayımı & $4.063(0.131)$ & JB \\
Ardışık Bağımlılık & $0.006(0.937)$ & LM \\
Farklı Varyanslık & $15.953(0.142)$ & Ki-kare \\
\hline
\end{tabular}

Not: Model tüm varsayımlardan geçmiştir.

Uzun dönem katsayılarına ilişkin CUSUM ve CUSUM Kare testleri Şekil 2'de verilmektedir. Şekil 2'deki grafikler incelendiği zaman yapısal kırılmanın varlığı açık bir şekilde görülmektedir. 
Şekil 2: (a) CUSUM ve (b) CUSUM Kare Testleri

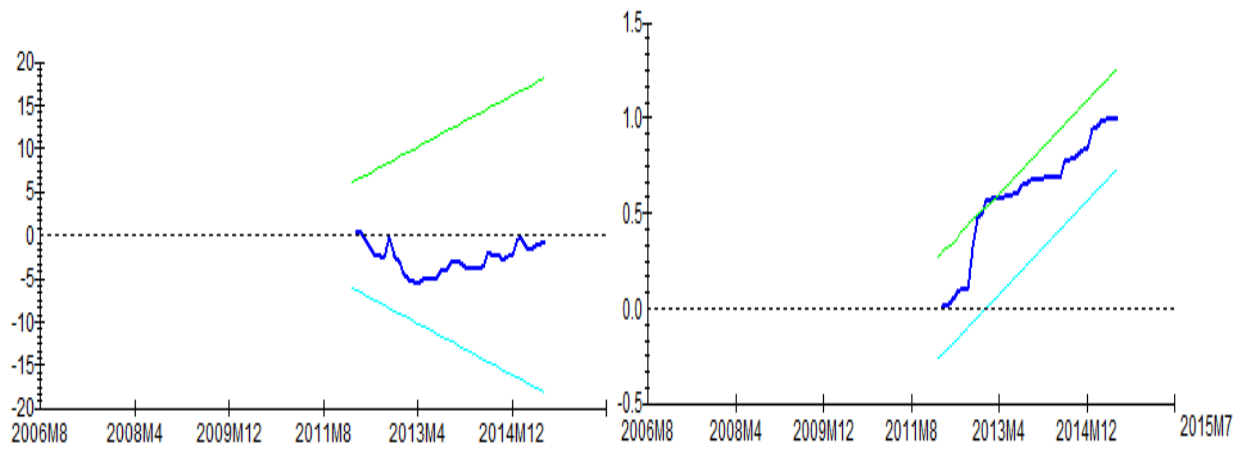

(a)

(b)

Uzun dönem ilişkisinden elde edilen hata teriminin bir gecikmeli değerinin modele eklenmesi ile oluşturulan kısa dönem katsayılarına ilişkin sonuçlar ise Tablo 8'de gösterilmektedir.

Tablo 8: ARDL $(3,4)$ ve Hesaplanan K1sa Dönem Katsayıları

\begin{tabular}{ccc}
\hline Değişkenler & Katsayı & $\begin{array}{c}\text { t istatistiği } \\
\text { (olas1lik değerleri) }\end{array}$ \\
\hline Sabit & 0.003 & $0.113(0.909)$ \\
$\Delta$ LTUTUN(-1) & -0.040 & $-0.147(0.882)$ \\
$\Delta$ LTUTUN(-2) & 0.135 & $0.602(0.548)$ \\
$\Delta$ LTUTUN(-3) & 0.154 & $1.176(0.242)$ \\
$\Delta$ LISZO & -0.221 & $-0.519(0.604)$ \\
$\Delta$ LISZO(-1) & 0.713 & $1.622(0.107)$ \\
$\Delta$ LISZO(-2) & -0.923 & $-\mathbf{2 . 0 7 1 ( 0 . 0 4 1})^{* *}$ \\
$\Delta$ LISZO(-3) & 0.034 & $0.076(0.939)$ \\
$\Delta$ LISZO(-4) & 0.313 & $0.731(0.466)$ \\
Kukla2007 & 0.005 & \\
Kukla2010 & -0.005 & $-0.169(0.866)$ \\
Kukla2012 & 0.006 & $0.220(0.826)$ \\
Hata(-1) & -0.856 & $\mathbf{- 2 . 8 3 0 ( 0 . 0 0 5 ) *}$ \\
\hline$R^{2}=0.481, \bar{R}^{2}=0.417, D W=1.997$ & \\
\hline
\end{tabular}

Hata teriminin bir gecikmeli değerinin negatif ve istatistiksel açıdan anlamlı olduğu görülmektedir. Bu değer, bir şokun ilk y1lda \%85 gibi büyük bir hızla dengeye yaklaştığını söylemektedir. Kukla değişkenlerin tamamının kısa dönemde anlamlı bir etkiye sahip olmadığı görülmektedir. İşsizlik oranlarının iki dönem gecikmeli değerinde meydana gelen \%1'lik bir artışın tütün üzerinden alınan vergilerde \%0.92 oranında bir azalışa neden olmaktadır. Kısa döneme ilişkin diagnostik istatistikler Tablo 9' da verilmektedir. 
Tablo 9: Kısa Döneme İlişkin Diagnostik Test Sonuçları

\begin{tabular}{ccc}
\hline & Test İstatistikleri & \\
& (Olasılık Değerleri) & Kullanılan Testler \\
\hline Normallik Varsayımı & $1.969(0.373)$ & JB \\
Ardışık Bağımlılık & $2.639(0.267)$ & LM \\
Farklı Varyanslık & $15.886(0.196)$ & Ki-kare \\
\hline
\end{tabular}

Kısa dönem diagnostik test sonuçları incelendiğinde, tahminlenen kısa dönem modeli için tüm varsayımların sağlandığı görülmektedir.

\section{SONUÇ}

Çalı̧̧abilme kabiliyetine sahip ve çalışma arzusunda olan bir birey işsizlik gibi sosyal ve ekonomik etkileri yoğun şekilde hissedilen bir durum ile karşılaştığında, kişisel davranışlarında farklılıklar ortaya çıkabilme ihtimali oldukça yüksektir. Özellikle bireyler alışkın oldukları yaşam şeklini kaybetmeme çabası gösterebilecek ve kendileri açısından önemli gördükleri alışkanlıklarından kolay kolay vazgeçemeyebilecektir. Nitekim sigara alışkanlığ 1 tiryakilik düzeyinde olan bir kişi işsiz kaldığında hemen sigarayı bırakma gibi bir ruh haline bürünmeyerek mevcut alışkanlığını devam ettirecek ve buna yönelik ya daha düşük fiyatlı sigara ile ya da sigarayı yasal olmayan piyasadan karşılama yolunu seçebilecektir. Sigara bağımlılığı düşük olan bir birey işsiz kaldığında ise zaten bağımlılığı düşük olduğu için sigarayı bırakma ve mevcut kaynaklarını farklı önceliklere göre kullanma yolunu seçebilecektir. Çalışmada elde ettiğimiz bulgular da bunu desteklemektedir. Öyle ki işsizlik ile sigara üzerinden alınan vergiler arasında kısa dönemde ters yönlü bir ilişki tespit edilmiştir. Yani işsizlik kısa dönemde vergi gelirlerinde azalmaya neden olabilecektir.

İşsizlik süresi uzadıkça yoğun sigara tüketen kişilerde mevcut depresif ruh halinin de etkisiyle günlük sigara içim adetlerinde artış meydana gelebilecektir. Zaten bu durumu destekler çalışmalar da mevcuttur. Sigarayı hafif içenler ve hiç içmeyenler açısından ise özellikle sosyal çevrelerinde diğer işsizlerle bir arada olmaya başlarlarsa sigara kullanma alışkanlığı elde edebilirler. $\mathrm{Bu}$ durumu destekler çeşitli çalışmalar bulunmaktadır. Bu yüzden de bu guruptaki kişiler de mevcut sigara içen gruba dahil olarak sigara tüketiminin artmasına katkıda bulunabileceklerdir. Zaten işsizliğin nispeten daha yüksek seyrettiği az gelişmiş ve gelişmekte olan ülkelerdeki sigara tüketim oranı gelişmiş ülkelerin çok daha üzerindedir. Böylece işsizliğin uzun dönemde sigara üzerinden alınan vergilerde artış yapması muhtemeldir. Çalışmada elde edilen bulgular da bunu desteklemektedir.

Kamu gelirleri açısından artırıcı bir etkisi olan sigara tüketiminin topluma yüklediği sosyal ve ekonomik maliyetler dikkate alındığında tartışmasız şekilde yoğun zararları ortaya çıkmaktadır. $\mathrm{Bu}$ durumun önlenmesi için mevcut politikaların artarak devam etmesinde ülkemiz açısından yarar bulunmaktadır. Özellikle sigara kullanan işsiz bireylerin sigara alışkanlıklarından kurtulmaları halinde işsizlik sigorta ödemelerinin süre ve miktar olarak artırılabileceği yasal 
hale getirilebilir. İşsizliğin yarattı̆̆ı tükenmişlik veya benzeri ruh halinin azaltılması amaciyla çeşitli sportif veya kültürel aktiviteler işsizlere devlet tarafından ücretsiz sağlanabilir. Sigara içmeyen veya bırakan işsizlerin iş başvurularında öncelikli sayılmaları ve bu kişileri istihdam edecek firmalara teşvik sağlanması gibi politikalar belirlenebilir. Elbette nihai hedef olarak işsizliğin mümkün düzeyde düşürülmesi önem arz etmektedir.

\section{KAYNAKÇA}

Arcaya, M., M.M. Glymour, N.A.Christakis, I.Kawachi, S.V. Subramanian. (2014). Individual and Spousal Unemployment as Predictors of Smoking and Drinking Behavior, PMC US National Library of Medicine National Institutes of Health, doi: 10.1016/j.socscimed.2014.03.034.

Barber S, S. M. Adioetomo, A. Ahsan ve D. Setyonaluri (2008) Tobacco Economics in Indonesia. Paris, International Union Against Tuberculosis and Lung Disease. http://www.worldlungfoundation.org/ht/a/GetDocumentAction/i/6567.

Bolton, K. L., E. Rodriguez. (2016). Smoking, Drinking and Body Weight After Re-employment: Does Unemployment Experience and Compensation Make a Difference?, BMC Public Health, http://www.medscape.com/vi ewarticle/710027_1.

Buck D., C. Godfrey, M. Raw ve M. Sutton (1995). Tobacco and jobs, Society for the Study of Addiction and Centre for Health Ecconomics. York, https://www.york.ac.uk/media/che/documents/papers/occasionalpapers/CHE\% 20Occasional\%20Paper\%2023.pdf.

Chaloupka, F. J , A. Yürekli, G.T. Fong, (2012). Tobacco Taxes as a Tobacco Control Strategy, Tob Control.; 21:2 172-180 doi:10.1136/tobaccocontrol-2011-050417.

Çalışkan, Ş. (2015). Üniversite Öğrencilerinin Sigara Kullanımını Etkileyen Faktörler (Ekonometrik Bir Yaklaşım), Uşak Üniversitesi Sosyal Bilimler Dergisi, 8/2, 23-48.

Emeç, H. \& E. Gülay. (2008). Alkol Tüketimi ve Sosyo-Demografik Değişkenlerin Alkol Tüketimi Üzerine Etkisi, Ekonomik Yaklaşım, Cilt:19, Sayı:68, ss.115-134. http://ekonomikyaklasim.org/pdfs2/EYD_V19_N68_A05.pdf.

Dickey, D.A \& Fuller, W.A. (1979). Distribution of Estimators for Autoregressive Time Series With A Unit Root, Journal Of American Statistical Association, 74, 427-431, doi: $10.2307 / 2286348$.

Falba,T., H.M. Teng, J.L. Sindelar, W.T. Gallo. (2005). The Effect of Involuntary Job Loss on Smoking Intensity and Relapse, PMC US National Library of Medicine National Institutes of Health, 100(9):1330-1339, doi: 10.1111/j.1360-0443.2005.01150.

Golden, S.D., Ribisl K.M., K.M. Perreira, (2014). Economic and Political Influence on Tobacco Tax Rates: A Nationwide Analysis of 31 Years of State Data, American Journal Public Health, 104 (2), 350-357, doi: 10.2105/AJPH.2013.301537.

Gülay, E. \& Pazarlıŏglu, M.V. (2008). Tasarruf ve Yatırım Arasındaki İlişskinin Sermaye Hareketliliği Üzerine Etkileri, D.E.Ü Sosyal Bilimler Enstitüsü, Yüksek Lisans Tezi.

Hammarström, A., U. Janlert. (1994). Unemployment and Change of Tobacco Habits: A Study of Young People from 16 to 21 Years of Age, PMCUS National Library of Medicine National Institutes of Health, 89(12):16911696. http://www.ncbi.nlm.nih.gov/pubmed/7866253.

Hu TW, Z. Mao, J. Shi ve C. Wendong (2008). Tobacco Taxation and Its Potential Impact in China. Paris, International Union Against Tuberculosis and Lung Disease. http://global.tobaccofreekids.org/files/pdfs/en/China_tobacc o_taxes_report_en.pdf.

Irvine I.J. ve Sims W.A. (1997). Tobacco Control Legislation and Ressource Allocation Effects. Canadian Public Policy, Vol:23, No:3, 259-273 doi:10.2307/3551571.

Jacobs, R., H. F. Gale, T. C. Capehart, P. Zhang, ve P. Jha. (2000). The Supply-side of Tobaccocontrol Policies. In: Jha P, Chaloupka F, eds., Tobacco Control in Developing Countries. Oxford, UK, Oxford University Press, 13;; 311- 
-341.http://siteresources.worldbank.org/INTETC/Resources/375990-10899 39172/309TO342.PDF.

Karaöz, M., M.Albeni, F.Büyüktatl1, (2010). Yasal Düzenlemelerin Sigara Tüketimi Üzerindeki Etkileri, Alanya Işletme Fakültesi Dergisi, 2/2, 19-36, http://dergipark.ulakbim.gov.tr/uaifd/article/viewFile/5000051254/5000048445.

Karvonen, S., P. Sipilä, P. Martikainen , O. Rahkonen, M. Laaksonen. (2008). Smoking in Context - a Multilevel Approach to Smoking Among Females in Helsinki. BMC Public Health., 8:134. doi: 10.1186/1471-2458-8-134.

Kılıç, D. (2014). Sigara Tüketiminin Panel Veri Analizi: İngiltere İçin Bir Uygulama, Gazi Üniversitesi İktisadi ve İdari Bilimler Fakültesi Dergisi, 16/3, 128-142, http://iibfdergisi.gazi.edu.tr/index.php/iibfdergisi/article/viewFile/ 743/ 569.

Mallick, H. \& Agarwal, S. (2005). Financial Liberalisation and Economic Growth In India: A Longrun Analysis, Institute of Economic Growth Ieg, elhi.

Mc Nicoll IH ve S. Boyle (1992). Regional Economic Impact of a Reduction of Resident Expenditure on Cigarettes: a Case Study of Glasgow. Applied Economics, Vol: 24, Issue:3, 291-296 doi:10.1080/00036849200000141.

Merwe Rovena, V. D.(1998a). Employment and Output Effects for Bangladesh Following a Decline in Tobacco Consumption. HNP Discussion Paper Series, Economics of Tobacco Discussion Paper, The World Bank.

Merwe Rovena, V. D. (1998b). Employment and Output Effects for Zimbabwe Following a Decline in Tobacco Consumption. HNP Discussion Paper Series, Economics of Tobacco Discussion Paper. Washington DC, The World Bank.

Merwe Rovena, V. D. \& Abedian I. (1999). Reduction in Consumer Expenditure on Cigarette and its Effects on Employment: A Case Study of South Africa. Contemp Econ Policy, 17:412422 doi:10.1111/j.1465--7287.1999.tb00693.

Montgomery, S.M., D.G. Cook, M.J. Bartley ve M.E.J. Wadworth. (1998). Unemployment, Cigarette Smoking, Alcohol Consumption and Body Weight in Young British Men ,

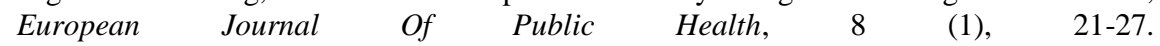
https://eurpub.oxfordjournals.org/content/eurpub/8/1/21.full.pdf.

Morris, J.K., D.G. Cook, A.G. Shaper. (1992). Non-employment and Changes in Smoking, Drinking, and Body Weight, British Medical Journal, 304 (6826), 536-541, http://www.ncbi.nlm.nih.gov/pubmed/1559056.

Oğuztürk, B.S., \& Y. Gülcü, (2012). Türkiye'de Sigara Tüketimini Etkileyen Faktörlerin Analizi, Uluslararası Alanya İşletme Fakültesi Dergisi, C:4, S:2, s. 99-105, http://alanyadergi.akdeniz.edu.tr/_dinamik/164/254.pdf.

Ohlander, E., M. Vikström, M. Lindström, K.Sundquist. (2006). Neighbour hood Non-employment and Daily Smoking: A population-based Study of Women and Men in Sweden, Eur J Public Health,. 16(1):78-84, doi: 10.1093/eurpub/cki047.

Önder, Z. \& A.A. Yürekli, (2016). Who Pays the Most Cigarette Tax in Turkey, Tob Control, 25:39-45 doi:10.1136/tobaccocontrol-2014-051639.

Pesaran, M. Hashem \& Shin, Yongcheol (1999). An Autoregressive Distributed Lag Modelling Approach to Cointegration Analysis, Cambridge Working Paper in Economics, No:9514, $1-35$.

Pesaran, M. Hashem, Shin, Yongcheol, Smith, Richard J. (2001). Bound Testing Approaches To The Analysis Of Long Run Relationships, Journal Of Applied Econometrics, special issue, 16, 289-326, doi: 10.1002/jae.616.

Phillips, Peter C.B. \& Perron, P. (1988). Testing For A Unit Root In Time Series Regression, Biometrika, 75(2), 335-346, doi: 10.1093/biomet/75.2.335.

Sakınç, S. \& S.Cura. (2012). Mali Sosyalleşme ve Kültür İlişkisi, Maliye Sosyolojisi Üzerine Denemeler (Editör: A.Kemal ÇELEBİ), Maliye Bakanlığı Strateji Geliştirme Başkanlığı Yayın No:2012/418, ss.33-61. https://www.sgb.gov.tr/SGBYayinlar/SunumMerkezi/index.html?ktp=2012-418.

Temiz, D. (2010). Sigara Tüketimini Etkileyen Faktörler Üzerine Bir Uygulama: Türkiye Örneği, Ekonomi Bilimleri Dergisi, Cilt 2, Say1 1, 2010 ISSN: 1309-8020. 
Wang, Q., J.J.Shen, C.Cochran. (2016). Unemployment Rate, Smoking in China: Are They Related?, Int J Environ Res Public Health, 13(1), 113, doi:10.3390/ijerph13010113.

Weden, M., N.M. Astone, D. Bishai. (2006). Racial, Ethnic, and Gender Differences in Smoking Cessation Associated with Employment and Joblessness Through Young Adulthood in the US, Social Science \& Medicine 62(2):303-316. DOI: 10.1016/J.SOCSCIMED.2005.06.009.

Vogli, R.D., M.Santinello. (2005). Unemployment and Smoking: Does Psychosocial Stress Matter?, Tob Control, 14:389-395 doi:10.1136/tc.2004.010611.

Zivot E. \& Andrews W. K. (1992). Further Evidence on the Great Crash, the Oil Price Stock and the Unit Root Hypothesis, Journal of Business and Economic Statistics, 10(3), 251-270, doi: $10.2307 / 1391541$.

http://www.haberturk.com/ekonomi/alisveris/haber/815756-sonunda-dustu

http://www.tuik.gov.tr/jsp/main/body/yay_tak.jsp;jsessionid=nXD3ShhhSTqh31JyTHJ8jQ9qL2C1

C2LLx22h11ZmT70NvJTXBW0D!1396409278?tk_id=13651\&d-5442-p=5\&alt_id=1007 


\section{SUMMARY}

Unemployment, which is defined as when people who have ability of working are not employed in the labor force, can examine by taking different socio-economic factors. For instance, it can be stated that unemployment may cause added value loss in terms of economy, financially impose a burden on government, and it may create the social unrest. Also, behavioral differences between individuals can occur because of unemployment. Particularly, it causes worsening behavioral situation related to health, and one of these behavioral situations is "smoking addiction".

The issue of consumption of cigarette has been attracting attention in recent years all over the world. The rising consumption of cigarette in accordance with increasing population is a consumption behavior in developing and developed countries. This situation holds for Turkey as well, and people tend to show tobacco use behavior in Turkey. It can be shown that the factors affecting consumption cigarettes are physiological condition of the person, social environment and economic conditions. On the other hand, the use of cigarette causes not only inherent cost on people who are smoking, but also external cost on people who are not smoking. Tax precautions called "sin taxes" in literature can be taken in order to prevent these exteriorities. Thus, it is possible to stop/reduce social behaviors that are not desirable socially thanks to taxation. There is a relationship between consumption of cigarette and taxes over cigarette. For this reason, if the consumption of cigarette increases, taxes on cigarette will rise. In addition to this, the relationship between unemployment and taxes on cigarette can be research subject for future works.

The objective of this study is to determine the relationship between the tobacco tax and unemployment rate in Turkey over the period 2006:1-2015:7. In this context, Unit root tests have been exploited to check the integration order of the variables, and the Autoregressive Distributed Lag Model including structural breaks is employed to explain the long-run relationship between the tobacco tax and unemployment rate. The findings of this study show that while an increase in unemployment rate is to raise tobacco tax in the long-run, an increase in unemployment rate is to decrease tobacco tax in the short-run.

As a matter of fact, when the period of time being unemployed is longer than usual, the persons who are smoking start to consuming more cigarettes every day. It is clearly seen that the papers in the literature supports this result. If people who do not smoke or smoke less spend time with the ones that are unemployment, they may active/re-active the habit of smoking. The consumption of cigarettes in underdeveloped or developing countries which have the highest unemployment rate is likely to be higher than the developed countries. For this reason, the longrun relationship between unemployment rate and taxes on cigarettes exist, and the findings in the study confirm the long-run relationship. 